\title{
Genetic isolation between two sympatric host plant races of the European corn borer, Ostrinia nubilalis Hübner. II: assortative mating and host-plant preferences for oviposition
}

\author{
M-T Bethenod ${ }^{1}$, Y Thomas ${ }^{1}$, F Rousset ${ }^{2}$, B Frérot ${ }^{3}$, L Pélozuelo ${ }^{3}$, G Genestier ${ }^{3}$ and D Bourguet ${ }^{1,4}$ \\ ${ }^{1}$ Unité Génétique Microbienne et Environnement, Institut National de la Recherche Agronomique, La Minière, Guyancourt 78285 , \\ France; 'Laboratoire Génétique et Environnement, Institut des Sciences de l'Evolution, Université de Montpellier II, Montpellier 34095, \\ France; ${ }^{3}$ Unité de Phytopharmacie et des Médiateurs chimiques, Institut National de la Recherche Agronomique Versailles, Route de \\ Saint-Cyr, 78026 Versailles Cedex, France; ${ }^{4}$ Centre de Biologie et de Gestion des Populations (CBGP), Institut National de la Recherche \\ Agronomique, Campus International de Baillarguet, CS 30 016, 34988 Montferrier sur Lez, France
}

The European corn borer, Ostrinia nubilalis Hübner, colonized maize (Zea mays L.) after its introduction into Europe about 500 years ago and is now considered one of the main pests of this crop. In northern France, two sympatric host races have been described: one feeding on maize and the other on mugwort (Artemisia vulgaris L.) and hop (Humulus lupulus L.). In a previous study, we showed that mating between the two races may be impeded by differences in the timing of moth emergence and in the composition of the sex pheromone produced by the females. In this study, we further investigated the genetic isolation of these two races using strains from the maize ( $Z$ strain) and mugwort ( $E$ strain) races selected for diagnostic alleles at two allozyme loci. In a cage containing maize and mugwort plants and located in natural conditions, mating between individuals of the same strain occurred more often than mating between males and females of the $E$ and $Z$ strains. In particular, we obtained no evidence for crosses between $Z$ females and $E$ males. We also found that females of the $Z$ strain laid their eggs almost exclusively on maize, whereas females of the $E$ strain laid their eggs preferentially, but not exclusively, on mugwort. These results suggest that the genetic differentiation between the two host races may also be favored by host-plant preference, one of the first steps toward sympatric speciation. Heredity (2005) 94, 264-270. doi:10.1038/sj.hdy.6800611 Published online 24 November 2004

Keywords: assortative mating; oviposition preference; sympatric speciation; sex pheromone; host races

\section{Introduction}

For several decades of the last century, speciation was thought to occur mainly, if not exclusively, in allopatric conditions. The importance of sympatric speciation has been reassessed over the last 25 years (Via, 2001), leading to an increase in the number of studies focusing on this particular type of speciation (Mallet, 2001; Via, 2001; Drès and Mallet, 2002). Although the importance of sympatric speciation is still debated (Turelli et al, 2001), various mathematical models have shown that speciation is theoretically possible even in the absence of geographical barrier to gene flow (Kondrashov and Mina, 1986; Kirkpatrick and Ravigné, 2002; Gavrilets, 2003). In addition, the number of biological models known to be undergoing, or to have undergone, sympatric speciation has increased (Drès and Mallet, 2002). Successful host shifts in phytophagous insects have been studied in

Correspondence: D Bourguet, Centre de Biologie et de Gestion des Populations, Institut National de la Recherche Agronomique, Campus International de Baillarguet, CS 30016, 34988 Montferrier sur Lez, France.E-mail: bourguet@ensam.inra.fr

Received 26 May 2004; accepted 8 September 2004; published online 24 November 2004 particular detail and are now considered one of the best routes for sympatric speciation (see Diehl and Bush, 1984; Via, 2001; Drès and Mallet, 2002). In these insects, the first step toward sympatric speciation involves genetically controlled changes in host preferences and adaptation to the newly colonized host plant. Following these changes, positive assortative mating between individuals adapted to the same host plant may be selected for, eventually leading to genetic differentiation between the two genetic entities and ultimately to speciation. In most studied cases, insects mate on or near their hosts (see Craig et al, 1997 and Prokopy et al, 1971 for striking examples and Drès and Mallet, 2002 for a review on host races) so that the premating isolation of host-plant races is a by-product of the disruptive selection initially induced by host plants.

In this study, we further investigated the genetic isolation of two sympatric host-plant races of the European corn borer (ECB), Ostrinia nubilalis (Lepidoptera: Crambidae). This polyphagous moth is native to northern Africa, western Asia and Europe (Hudon et al, 1989), and was accidentally introduced into North America at the beginning of the 20th Century (Baker et al, 1949). O. nubilalis feeds on more than 200 weeds and 
cultivated plants (Hodgson, 1928; Ponsard et al, 2004) and colonized maize (Zea mays L.) after its introduction into Europe about 500 years ago. In France, ECB populations feeding on maize are genetically differentiated from those feeding on mugwort (Artemisia vulgaris L.) and hop (Humulus lupulus L.) (Bourguet et al, 2000; Martel et al, 2003; Bontemps et al, 2004). The exact taxonomic status of these two genetic entities has not yet been defined. In this paper, as in that by Thomas et al (2003), we use the terms 'maize race' to indicate a population feeding on maize and 'mugwort race' for a population feeding on either mugwort or hop.

Genetic isolation between sympatric populations of the maize and mugwort ECB host races may result from both differences in the date of moth emergence and differences in the mating communication system (Thomas et al, 2003; Pélozuelo et al, 2004). In France, at a field site near Paris, mugwort-race moths emerged, on average, 10 days earlier than maize-race moths. This allochrony in the timing of emergence may be a major, but not absolute, cause of isolation between the two races, as the lifetime of ECB adults is estimated at around 10 days (Balachowsky, 1935; Fadamiro and Baker, 1999). At the same field site, females of the two host races produced sex pheromones with different $E: Z$ ratios of the $\Delta$-11-tetradecenyl acetate $(\Delta 11-14: A c)$ isomers. This difference in the mating communication system between the two host-plant races is not restricted to this particular site. All but two females out of 169 collected on mugwort or hop at eight other sites distributed throughout France produced a pheromone blend with a 97:3 ratio (E blend) of the $E$ and $Z$ isomers of $\Delta 11-14$ :Ac (Pélozuelo et al, 2004). Conversely, all but one of the176 females extracted from maize stalks collected at six different sites - located in the center and south of France - produced a pheromone blend with a 1:99 E: $Z$ isomeric ratio ( $Z$ blend) (Pélozuelo et al, 2004). Only three females - one on each type of host plant - of the $\sim 350$ analyzed produced a pheromone with a 50:50 E:Z ratio of $\Delta 11-14$ :Ac isomers (Pélozuelo et al, 2004). These three females were probably hybrid females. Hence, to our knowledge, females producing a $\mathrm{Z}$ pheromone blend have never been detected on populations collected on mugwort or hop. Similarly, females producing an E pheromone blend have never been detected in maize fields located in France. We therefore suggest that ECB larvae of the mugwort race can hardly develop on maize and that larvae of the maize race find it difficult to develop on mugwort and hop, and/or that ECB females prefer to lay their eggs on the host plants corresponding to their own race. The small proportion of hybrid females (three in $\sim 350$ ) may be a consequence of strong assortative mating between the host races and/or poor hybrid larval development on maize, hop and mugwort.

We investigated female preferences for oviposition and assortative mating between males and females of the two host races of ECB. We selected two strains, one from the maize race ( $Z$ strain) and one from the mugwort race (E strain), for diagnostic alleles at two allozyme loci. Using these strains, we addressed two questions related to host-race formation in O. nubilalis. Firstly, we investigated whether mating between the two strains was random in the absence of temporal barriers and in complete sympatry. Secondly, we investigated whether females of the two strains displayed host-plant preferences for oviposition.

\section{Materials and methods}

\section{ECB strains}

Origin of the strains: This experiment was performed with two strains, referred to as the E and $\mathrm{Z}$ strains. The E strain was established from 195 overwintering larvae collected from hop ( $H$. lupulus L.) during the fall of 1999 at Obernai (Alsace, France). These larvae were maintained at $4{ }^{\circ} \mathrm{C}$ for diapause completion in laboratory conditions. During spring 2000, overwintering larvae were placed under diapause-breaking conditions $\left(25^{\circ} \mathrm{C}\right.$ under a 16:8 h (L:D) photoperiod, in plastic cups containing a moistened piece of cotton wool). We recovered 135 individuals, which were used to establish the E strain. We analyzed the composition of the pheromones produced by 12 females collected randomly within the batch of this strain. Consistent with previous results (Thomas et al, 2003; Pélozuelo et al, 2004), these females produced the E pheromone blend. The $Z$ strain was established from eight egg masses (approximately 120 to 160 eggs) collected in maize fields during July 1998 at Les Rues des Vignes (Nord-Pas-deCalais, France). The composition of the pheromones produced by 24 females of this strain was analyzed. Consistent with previous results (Thomas et al, 2003; Pélozuelo et al, 2004), these females produced the $Z$ pheromone blend.

Selection for diagnostic allozyme markers: The genetic diversity of each strain was investigated by starch gel allozyme electrophoresis for five unlinked autosomal loci (Hbdh, Pgm, Mpi, Aat and Gpi) and one sex-linked locus (Tpi), as described previously (Bourguet et al, 2000). No diagnostic allele was found for any of the loci studied. However, as expected from previous results obtained on populations collected on the two host races (Bourguet et al, 2000; Martel et al, 2003; Thomas et al, 2003; Bontemps et al, 2004), the two strains were genetically differentiated at two loci: Tpi and Mpi. At the Tpi locus, the frequency of the Tpi 100 allele was significantly higher in the E strain than in the Z strain, whereas the Tpi 120 allele was significantly more frequent in the $Z$ strain than in the E strain. At the Mpi locus, the Mpi 80 and Mpi 100 alleles were the main alleles in the $\mathrm{Z}$ and $\mathrm{E}$ strains, respectively.

Using isofemale lines, we selected both strains for homozygosity at the Tpi and Mpi loci. The selected E and $Z$ strains were established from the progenies of one and two isofemale lines, respectively. At the Tpi locus, the E strain was fixed for the Tpi 100 allele, whereas the $\mathrm{Z}$ strain was fixed for the Tpi 120 allele. At the Mpi locus, the E and Z strains were fixed for the Mpi 100 and Mpi 80 alleles, respectively. Fixation of these diagnostic alleles made it possible to discriminate between the various intra- and interstrain crosses occurring in the experiment described below.

The selection process led to both strains being highly inbred, resulting in a decrease in genetic diversity. Consequently, the mating choices and host-plant preferences for oviposition displayed by the $\mathrm{E}$ and $\mathrm{Z}$ strains may be less variable than those displayed by $E$ and $Z$ 
moths in natural populations. However, there is no $a$ priori reason that the process by which we fixed the diagnostic alleles resulted in selection of any of these two traits. Indeed, the reproductive success of ECB females during the rearing was not altered by their possible hostplant preference, as the substrate provided to lay eggs was presumably neutral: it consisted of a sheet of paper (not a particular plant) placed at the top of the breeding cages. Likewise, possible differences in propensity to favor assortative mating among females should not have affected their reproductive success in our experiment. The extent of assortative mating and host-plant preferences for oviposition may have been unintentionally increased - via genetic drift or due to genetic variations being in linkage disequilibrium with the Mpi and Tpi alleles fixed in the strains - but there is little chance that these traits were not initially present in the natural populations used to create the strains. Hence, although their importance may have been artificially magnified, the mating choices and oviposition preferences observed in this experiment are probably real differences between the maize and mugwort ECB races.

\section{Study site and experimental setting}

Study site and cage setting: The experiment took place from spring 2001 to summer 2002 at a field site located at the vicinity of the INRA laboratory at Guyancourt (Ilede-France, France, $02^{\circ} 04^{\prime} \mathrm{N}, 48^{\circ} 46^{\prime} \mathrm{E}$ ). In this field, we set up a 2-m-high cage covering a ground area of $81 \mathrm{~m}^{2}$ $\left(9 \times 9 \mathrm{~m}^{2}\right)$, covered by a net. In May 2001, mugwort $(A$. vulgaris L.) was planted and maize (Z. mays L.) sown in the cage in the following pattern: three rows of mugwort separated by two strips of three rows of maize. Each row of maize contained about 90 plants and each row of mugwort contained about 15 plants. In total, the cage contained $\sim 540$ stalks of maize and $\sim 45$ stands of mugwort (each stand of mugwort had around 10 stalks).

Moth releases: From 12 June to 30 July 2001, a total of 127 virgin males of each strain (isolated from females as pupae) were introduced into the cage. During the same period, we released a total of 127 and 123 virgin females of the $\mathrm{Z}$ and $\mathrm{E}$ strains, respectively. The males of the two strains were the same age and were systematically introduced in identical numbers so that the probabilities of a female mating with a male of her own strain or with a male from the other strain were equal. Crosses, and the individuals obtained from these crosses, were expressed in the form 'female strain $\times$ male strain' (either $\mathrm{E}$ or $\mathrm{Z}$ in each case). For instance, $\mathrm{E} \times \mathrm{Z}$ is a cross between an $\mathrm{E}$ female and a $\mathrm{Z}$ male.

\section{Egg mass collection and development in laboratory conditions}

On six dates (23-27 and 30 July 2001), all maize and mugwort plants in the cage were carefully screened for the presence of egg masses on their leaves and on their stalks. All egg masses encountered during these screenings were immediately collected and brought back to the laboratory. For each egg mass, the plant species from which it was collected, the number of eggs and the percentage hatching were recorded. The offspring of each egg mass were reared in laboratory conditions $\left(25^{\circ} \mathrm{C}\right.$ under a 16:8 $\mathrm{h}$ (L:D) photoperiod) until the adult stage.
Larvae were fed on the maize flour-wheat germ-agar artificial diet described by Gahukar (1975). This diet contained fumidil to control Nosema infection and benzoic acid as a preservative. For each egg mass, we recorded the number and sex of emerged moths. These moths were then weighed and frozen at $-80^{\circ} \mathrm{C}$ until electrophoretic analysis of the Tpi and Mpi loci.

\section{Enzyme electrophoresis}

Allozyme electrophoresis was performed on each moth emerged from any of the egg masses collected in the cage. We determine the genotype of individual at the $\mathrm{Mpi}$ and Tpi loci as described previously (Bourguet et al, 2000) to identify the strain(s) of its parents. Male genotypes at these two loci allow discrimination between $\mathrm{E} \times \mathrm{E}, \mathrm{Z} \times \mathrm{Z}$ and interstrain parental crosses. Females being hemiploid at the Tpi sex-linked locus, female genotypes additionally allow discrimination between $\mathrm{Z} \times \mathrm{E}$ and $\mathrm{E} \times \mathrm{Z}$ parental crosses (Table 1 ).

\section{Data analysis}

We investigated whether individuals mated randomly regardless of strain by testing for a deviation of the observed frequencies of the three types of crosses (ie $\mathrm{E} \times \mathrm{E}, \mathrm{Z} \times \mathrm{Z}$ or interstrain crosses) from those theoretically expected under the hypothesis of random mating (ie genotypic frequencies expected under HardyWeinberg equilibrium conditions). For this, we used the corresponding test in the GENEPOP 3.3 software (Raymond and Rousset, 1995).

\section{Results}

\section{Mating choice}

During the last week of July, 178 egg masses were collected from the two host plants (A. vulgaris and $Z$. mays). Of these egg masses, $13(7.3 \%)$ were sterile, six (3.4\%) did not give rise to a single adult and nine $(5.1 \%)$ gave a few moths for which electrophoresis patterns could not be interpreted. We analyzed genotypic composition at the Tpi and Mpi loci for the progenies of the 150 remaining egg masses. This enabled us to determine the genotype of the female that laid each egg mass and of the male that mated with this female (see Table 1). As females may lay egg masses on several consecutive days, the relative proportions of egg masses on any one day were not independent from those on previous days. The results were therefore analyzed separately for each sampling date. During the week of

Table 1 Tpi and Mpi genotypes of male and female offspring of the four types of cross between the parental $\mathrm{E}$ and $\mathrm{Z}$ strains

\begin{tabular}{|c|c|c|c|c|}
\hline \multirow[t]{3}{*}{ Crosses } & \multicolumn{4}{|c|}{ Offspring genotypes } \\
\hline & \multicolumn{2}{|c|}{ Mpi } & \multicolumn{2}{|l|}{ Tpi } \\
\hline & Males & Females & Males & Females \\
\hline $\mathrm{E} \times \mathrm{E}$ & Mpi 100/Mpi 100 & Mpi 100/Mpi 100 & Tpi 100/Tpi 100 & Tpi 100 \\
\hline$E \times Z$ & Mpi 80/Mpi 100 & Mpi 80/Mpi 100 & Tpi 100/Tpi 120 & Tpi 120 \\
\hline $\mathrm{Z} \times \mathrm{E}$ & Mpi 80/Mpi 100 & Mpi 80/Mpi 100 & Tpi 100/Tpi 120 & Tpi 100 \\
\hline $\mathrm{Z} \times \mathrm{Z}$ & Mpi 80/Mpi 80 & Mpi 80/Mpi 80 & Tpi 120/Tpi 120 & Tpi 120 \\
\hline
\end{tabular}

The first letter of a cross corresponds to the female. 
sampling, the relative proportions of egg masses originating from $\mathrm{E} \times \mathrm{E}$ and $\mathrm{Z} \times \mathrm{Z}$ crosses varied between 43 and $88 \%$ and between 0 and $35 \%$, respectively (Table 2 ). The relative proportion of egg masses originating from interstrain $(Z \times E$ and $E \times Z)$ crosses ranged between 0 and $26 \%$ (Table 2). At five of the six sampling dates, the proportions of hybrid egg masses were significantly lower than expected if random mating occurred between moths of the two strains (Table 2). At these dates, the estimator $\hat{f}$ of $F_{\text {IS }}$ ranged from 0.537 to 1.000 . Finally, only one of the two types of hybrid cross, $\mathrm{Z}$ females $\times \mathrm{E}$ males, resulted in the production of fertile egg masses during the week of sampling.

\section{Oviposition on mugwort and maize}

Only one of 47 (2\%) egg masses laid by Z females was collected on mugwort, all others (98\%) were collected on maize (Table 3). The deviation of the relative proportion of egg masses laid by $\mathrm{Z}$ females on both plant species from 50:50 was found statistically significant $(P<0.05)$ on four of the six sampling dates (Table 3 ). A total of $103 \mathrm{egg}$ masses laid by E females were collected: 15 on maize (or $15 \%$ overall, varying between 10 and $22 \%$ depending on sampling day) and $88(85 \%)$ on mugwort (Table 3$)$. The deviation of the relative proportion of egg masses laid by E females on both plant species from 50:50 was found statistically significant $(P<0.05)$ on five of the six sampling dates.

\section{Discussion}

Assortative mating between the selected $E$ and $Z$ strains In our experiment, the moths introduced into the cages did not mate at random: mating between individuals of the same strain occurred more often than mating between males and females of the $\mathrm{E}$ and $\mathrm{Z}$ strains. Indeed, on all sampling dates, the proportion of hybrid egg masses in the cage was lower than that expected under Hardy-Weinberg equilibrium. Females of the ECB can lay several egg masses during a night. Consequently, the number of the different types $(E, Z$ or hybrid) of egg mass is not an ideal direct estimate of the numbers of each type of mating. However, laboratory observations showed that $\mathrm{E}$ and $\mathrm{Z}$ females laid a similar mean number of egg masses per night ( $Y$ Thomas, unpublished data). Hence, the number of the different types of egg mass should be roughly proportional to the frequency of each type of mating occurring in the cage. This estimate might be further biased because egg masses for which the offspring were not analyzed - because they were sterile, because all the offspring died before reaching the adult stage or because electrophoresis was not of sufficient quality for reliable interpretation - may have been laid preferentially following a particular type of mating. However, even if all these unanalyzed egg masses were laid by $E \times Z$ and/or $Z \times E$ crosses, the proportion of hybrid

Table 2 Proportion of egg masses laid following each type of cross, for several sampling dates and for all dates

\begin{tabular}{|c|c|c|c|c|c|c|c|c|c|c|}
\hline \multirow[t]{2}{*}{ Date } & \multirow[t]{2}{*}{$\mathrm{N}$ total } & \multirow[t]{2}{*}{$\mathrm{N}$ fertile } & \multirow[t]{2}{*}{$\mathrm{N}$ with adults } & \multirow[t]{2}{*}{$\mathrm{N}$ analyzed } & \multicolumn{4}{|c|}{ Crosses } & \multirow[t]{2}{*}{$\hat{\mathrm{f}}^{\mathrm{a}}$} & \multirow[t]{2}{*}{ P-value } \\
\hline & & & & & $E \times E$ & $Z \times Z$ & $Z \times E$ & $E \times Z$ & & \\
\hline 23 July 01 & 28 & 25 & 25 & 25 & 0.88 & 0.08 & 0.04 & 0 & 0.786 & 0.007 \\
\hline 24 July 01 & 19 & 18 & 17 & 16 & 0.63 & 0.25 & 0.12 & 0 & 0.725 & 0.008 \\
\hline 25 July 01 & 28 & 24 & 23 & 20 & 0.65 & 0.35 & 0.00 & 0 & 1.000 & $<10^{-5}$ \\
\hline 26 July 01 & 23 & 22 & 22 & 21 & 0.43 & 0.33 & 0.24 & 0 & 0.537 & 0.025 \\
\hline 27 July 01 & 25 & 23 & 22 & 19 & 0.74 & 0.00 & 0.26 & 0 & -0.125 & 1.000 \\
\hline 30 July 01 & 55 & 53 & 50 & 49 & 0.72 & 0.20 & 0.08 & 0 & 0.783 & $<10^{-5}$ \\
\hline All dates & 178 & 165 & 159 & 150 & 0.69 & 0.20 & 0.11 & 0 & & \\
\hline
\end{tabular}

${ }^{\mathrm{a}} F_{\mathrm{IS}}$ estimator of Weir and Cockerham (1984).

bProbability of deviation from Hardy-Weinberg equilibrium.

$N$ total $=$ number of egg masses collected; $N$ fertile $=$ number of egg masses that produced offspring; $N$ with adults $=$ number of egg masses that produced adult offspring; $N$ analyzed = number of egg masses that produced adults with interpretable electrophoresis patterns.

The first letter of a cross corresponds to the female.

Table 3 Proportion of egg masses laid by each type of female on each of the two host plants for several dates and for all dates

\begin{tabular}{|c|c|c|c|c|c|c|c|c|c|c|c|c|}
\hline \multirow[t]{2}{*}{ Date } & \multicolumn{6}{|c|}{ Females Z } & \multicolumn{6}{|c|}{ Females $E$} \\
\hline & $\mathrm{N}$ & Maize & Mugwort & $\chi^{2}$ & $\mathrm{df}$ & P-value & $\mathrm{N}$ & Maize & Mugwort & $\chi^{2}$ & df & P-value \\
\hline 23 July 01 & 3 & 1.00 & 0.00 & 3.000 & 1 & 0.083 & 22 & 0.14 & 0.86 & 11.636 & 1 & $<10^{-3}$ \\
\hline 24 July 01 & 6 & 1.00 & 0.00 & 6.000 & 1 & 0.014 & 10 & 0.10 & 0.90 & 6.400 & 1 & 0.011 \\
\hline 25 July 01 & 7 & 1.00 & 0.00 & 7.000 & 1 & 0.008 & 13 & 0.15 & 0.85 & 6.231 & 1 & 0.013 \\
\hline 26 July 01 & 12 & 1.00 & 0.00 & 12.000 & 1 & $<10^{-3}$ & 9 & 0.22 & 0.78 & 2.778 & 1 & 0.096 \\
\hline 27 July 01 & 5 & 0.80 & 0.20 & 1.800 & 1 & 0.180 & 14 & 0.14 & 0.86 & 7.143 & 1 & 0.008 \\
\hline 30 July 01 & 14 & 1.00 & 0.00 & 14.000 & 1 & $<10^{-3}$ & 35 & 0.14 & 0.86 & 17.857 & 1 & $<10^{-4}$ \\
\hline All dates & 47 & 0.98 & 0.02 & & & & 103 & 0.15 & 0.85 & & & \\
\hline
\end{tabular}

Details of the test for difference between the observed proportions of egg masses on each type of host plant compared with an equal proportion on each host plant (ie $50 \%$ on maize and $50 \%$ on mugwort). 
crosses would remain significantly (on July 25 and 30) or almost significantly (on July 23 and 26) lower than expected if the moths had mated randomly. Thus, the low proportion of hybrid egg masses is at least partly, if not entirely, due to positive assortative mating of the two strains.

Mating between the two strains was not symmetric. Indeed, none of the 150 egg masses analyzed during the experiment was laid by females of the E strain after mating with a $Z$ male. All the 17 hybrid egg masses found were laid by $Z$ females after $Z \times E$ crosses. As both $E \times Z$ and $Z \times E$ hybrids can be obtained in the laboratory ( $Y$ Thomas unpublished results), the absence of $\mathrm{E} \times \mathrm{Z}$ egg masses from the analysis is unlikely to be entirely due to postzygotic isolation. The asymmetry in the hybrid crosses may be rather due to the difference in male responses to the pheromone blends. Indeed, in laboratory conditions, $\mathrm{Z}$ males do not respond to the $\mathrm{E}$ blend, whereas a few $E$ males respond to the $\mathrm{Z}$ blend (Glover et al, 1990). It is worth noting that, in North American field populations located in the state of New York, the few hybrid females recovered by Glover et al (1991) were consistent with hybridization occurring, like in the present study, by E males mating with $\mathrm{Z}$ females.

In most studies of phytophagous insects, mating has been shown to take place on or near the host plants (Prokopy et al, 1971, 1972; Craig et al, 1997; Via, 1999). In these species, assortative mating between host races is thought to evolve as a by-product of the host shift (Rice 1984, 1987). Indeed, for the host races described to date, assortative mating is often weak in the absence of the host plant (eg Craig et al, 1993; Feder et al, 1994). Our experiment cannot rule out the influence of the host plant as $E \times E$ and $Z \times Z$ mating may have occurred on mugwort and maize, respectively. However, the influence of the host plant on assortative mating is probably limited since the ECB frequently mates on nonhost plants in the field (Showers et al, 1976).

\section{Host-plant preferences for oviposition}

Preferences for oviposition are a common feature among host races of herbivorous insects (Drès and Mallet, 2002). For example, the larch budmoth has two host races, one feeding on larch and the other on pine (Emelianov et al, 2001). Females of the larch race display a strong preference for larch, but are occasionally found on pine, whereas females of the pine race are attracted mainly, but not exclusively, to pine (Emelianov et al, 2003). In the experiment described here, females of the two strains displayed striking differences in the relative proportions of egg masses laid on the two host plants. Females of the $Z$ strain laid their egg masses almost exclusively on maize. Conversely, females of the E strain laid their egg masses preferentially, but not exclusively, on mugwort. If we assume that oviposition at random would have resulted in an equal proportion of egg masses laid on the two host plants, then both $\mathrm{Z}$ and $\mathrm{E}$ females displayed a significant preference for laying their egg masses on maize and mugwort, respectively.

The $\mathrm{Z}$ strain was selected from a population collected on maize, whereas the E strain originated from diapausing larvae collected on hop, one of the host plants of the mugwort race (Bourguet et al, 2000; Bontemps et al, 2004). Our results therefore indicate that both strains preferred to lay their egg masses on the host plants of their own host races. Each of the host races of Rhagoletis pomonella is also most strongly attracted to its own natural host plant. Differences in the attractions of the host races of $R$. pomonella are based primarily on the volatile compounds produced by the host (Linn et al, 2003), in addition to visual cues helping the adults to find fruits within the tree canopy (Prokopy and Roitberg, 1984).

\section{Implications for the evolution of the two host races}

One of the factors that may reduce the frequency of hybridization between the maize and mugwort races is a difference in the timing of moth emergence (Thomas et al, 2003). In this experiment, the mating choices of $E$ and $Z$ moths occurred in the absence of allochronic barriers as $E$ and $\mathrm{Z}$ moths were introduced into the cage at the same age. A second factor that may reduce the frequency of hybrid crosses is that moths emerging from maize use the $\mathrm{Z}$ pheromone blend, whereas moths emerging from hop and mugwort use the $E$ pheromone blend (Thomas et al, 2003; Pélozuelo et al, 2004). Female sex pheromones provide long-range cues for mate-finding (Löfstedt, 1993). In the $9 \times 9 \mathrm{~m}^{2}$ cage into which the $E$ and $Z$ strains were introduced, the influence of female sex pheromone was probably less important than in natural populations. Assortative mating probably resulted from unknown proximate cues in mate choice, although we cannot rule out an effect of the female sex pheromone.

Of the $\sim 350$ females analyzed by Pélozuelo et al (2004), none of those collected on maize produced the E blend and none of those produced on hop and mugwort produced the $\mathrm{Z}$ pheromone blend. Three of these females produced an intermediate ratio of $E: Z$ isomers of $\Delta 11-$ 14:Ac, characteristic of hybrid females (Pélozuelo et al, 2004). The results reported here provide a potential explanation of the relative proportions of $E, Z$ and hybrid moths on maize and mugwort. Indeed, in most regions of France, $\mathrm{Z}$ moths emerging from maize are far more numerous than $E$ moths emerging from mugwort and hop - in France maize is grown on 3 million hectares, most of which being significantly infested by the ECB, while mugwort and most of the hop are wild-growing plants. Consequently, even if there were no barrier limiting $Z \times E$ hybrid crosses, such crosses would certainly occur at a much lower frequency than $Z \times Z$ crosses. If $Z$ females lay their eggs exclusively on maize like the females of the $Z$ strain in our experiment - then hybrid larvae feeding in maize fields are likely to be much rarer than $Z$ larvae, which may account for such larvae being detected in only very small numbers in the data set of Pélozuelo et al (2004). However, the difference in the density of moths emerging from maize and mugwort may favor $\mathrm{E} \times \mathrm{Z}$ hybrid crosses over $\mathrm{E} \times \mathrm{E}$ crosses. As $E$ females preferred to lay their egg masses on mugwort rather than on maize, substantial quantities of hybrid larvae would be expected to feed on mugwort. The data reported by Thomas et al (2003) and Pélozuelo et al (2004) showed that this is clearly not the case: overall, in populations collected on mugwort, the proportion of hybrids was $<1 \%$. Our work provides a rational explanation for this very low proportion of hybrids on mugwort, as females of the E strain seem to have mated exclusively with E males. 


\section{Conclusions}

This study provides new insight into genetic isolation between the two sympatric ECB host races. Thomas et al (2003) showed that assortative mating between these races may occur due to differences in the moth emergence timing, with mugwort-race moths emerging, on average, 10 days earlier than maize-race moths. We show here that even in situations of true sympatry and synchrony, the level of hybridization between the maize and mugwort races is lower than expected under a random mating hypothesis. This reduction may be the consequence of the difference in sex pheromone between the two host races or other undetermined cues.

Thomas et al (2003) showed that males emerged earlier than females in both host races, favoring one type of hybrid cross ( $E$ mugwort females $\times Z$ maize males) over the other ( $Z$ maize females $\times E$ mugwort males). If the pattern of mating choice observed in this experiment accurately reflects that occurring in natural conditions, then the hybrid cross (ie $\mathrm{Z}$ maize females $\times \mathrm{E}$ mugwort males), which is the most likely to occur in sympatric conditions, may be disfavored by differences in the timing of moth emergence between the two host races and between males and females. In other words, one type of hybrid ( $\mathrm{E}$ mugwort females $\times \mathrm{Z}$ maize males) would be mostly prevented by the evolution of specific mating choice, whereas the other ( $\mathrm{Z}$ maize females $\times \mathrm{E}$ mugwort males) would be indirectly disfavored by adaptation to ecological conditions, that is, an indirect consequence of the difference in emergence timing between the two host races.

Our results suggest that the genetic differentiation between these two host races may also be favored by host-plant preference, one of the first steps toward sympatric speciation (Kondrashov and Mina, 1986; Drès and Mallet, 2002). However, the host-plant preference for oviposition of the $\mathrm{E}$ and $\mathrm{Z}$ strains requires confirmation in moths collected from natural populations. Differences in performance on the host plants (Kondrashov and Mina, 1986; Drès and Mallet, 2002) should also be investigated.

\section{Acknowledgements}

We thank Richard Bailey and Sergine Ponsard for very helpful comments and Alain Weissenberger for collecting ECB larvae at Obernai. This work was supported by the INRA AIP 'Organismes Génétiquement Modifiés et Environnement' and by the MENRT AO 'Impact des OGM'. This is publication ISEM No. 2004-059.

\section{References}

Baker WA, Bradley WG, Clark CA (1949). Biological control of the European corn borer in the United States. Tech Bull 983: $1-185$.

Balachowsky M (1935). Les insectes nuisibles aux céréales et aux graminées. Les insectes nuisibles aux plantes cultivées: Paris.

Bontemps A, Bourguet D, Pélozuelo L, Bethenod M-T, Ponsard $S$ (2004). Managing the evolution of $B t$ resistance in natural populations of the European corn borer, Ostrinia nubilalis: host plant, host race and pherotype of adult males at aggregation sites. Proc $R$ Soc Lond Ser B (in press).

Bourguet D, Bethenod M-T, Trouve C, Viard F (2000). Host-plant diversity of the European corn borer Ostrinia nubilalis: what value for sustainable transgenic insecticidal Bt maize? Proc $R$ Soc Lond Ser B 267: 1177-1184.

Craig TP, Horner JD, Itami JK (1997). Hybridization studies on the host races of Eurosta solidaginis: implications for sympatric speciation. Evolution 51: 1552-1560.

Craig TP, Itami JK, Abrahamson WG, Horner JD (1993). Behavioral evidence for host-race formation in Eurosta solidaginis. Evolution 47: 1696-1710.

Diehl SR, Bush GL (1984). An evolutionary and applied perspective of insect biotypes. Annu Rev Entomol 29: 471-504.

Drès M, Mallet J (2002). Host races in plant-feeding insects and their importance in sympatric speciation. Philos Trans $R$ Soc Lond Ser B 357: 471-492.

Emelianov I, Drès M, Baltensweiler W, Mallet J (2001). Hostinduced assortative mating in host races of the larch budmoth. Evolution 55: 2002-2010.

Emelianov I, Simpson J, Narang P, Mallet J (2003). Host choice promotes reproductive isolation between host races of the larch budmoth. J Evol Biol 16: 208-218.

Fadamiro HY, Baker TC (1999). Reproductive performance and longevity of female European corn borer, Ostrinia nubilalis: effects of multiple mating, delays in mating, and adult feeding. J Insect Physiol 45: 385-392.

Feder JL, Opp SB, Wlazlo B, Reynolds K, Go W, Spisak S (1994). Host fidelity is an effective premating barrier between sympatric races of the apple maggot fly. Proc Natl Acad Sci USA 91: 7990-7994.

Gahukar RT (1975). Nouvelles techiques adoptées pour l'élevage d'Ostrinia nubilalis Hübner sur milieu artificiel. Ann Zool Ecol Anim 7: 491-498.

Gavrilets S (2003). Perspective: models of speciation: what have we learned in 40 years? Evolution 57: 2197-2215.

Glover TJ, Campbell M, Robbins PS, Roelofs WL (1990). Sexlinked control of sex pheromone behavioral responses in European corn borer moths (Ostrinia nubilalis) confirmed with TPI marker gene. Arch Insect Biochem Physiol 15: 67-77.

Glover TJ, Knodel JJ, Robbins PS, Eckenrode CJ, Roelofs WL (1991). Gene flow among three races of European corn borer (Lepidoptera: Pyralidae) in New York State. J Econ Entomol 20: $1356-1362$.

Hodgson BE (1928). The host plants of the European Corn Borer in New England. USDA Tech Bull 77: 1-63.

Hudon M, LeRoux EJ, Harcourt DG (1989). Seventy years of European corn borer (Ostrinia nubilalis) research in North America. Agric Zool Rev 3: 53-96.

Kirkpatrick M, Ravigné V (2002). Speciation by natural and sexual selection: models and experiments. Am Nat 159: S22-S35.

Kondrashov AS, Mina MV (1986). Sympatric speciation: when is it possible? Biol J Linn Soc 27: 201-223.

Linn Jr C, Feder JL, Nojima S, Dambroski HR, Berlocher SH, Roelofs W (2003). Fruit odor discrimination and sympatric host race formation in Rhagoletis. Proc Natl Acad Sci USA 100: 11490-11493.

Löfstedt C (1993). Moth pheromone genetics and evolution. Philos Trans R Soc Lond Ser B 340: 167-177.

Mallet J (2001). The speciation revolution. J Evol Biol 14: 887-888.

Martel C, Réjasse A, Rousset F, Bethenod M-T, Bourguet D (2003). Host-plant-associated genetic differentiation in Northern French populations of the European corn borer. Heredity 90: 141-149.

Pélozuelo L, Malosse C, Genestier G, Guenego H, Frérot B (2004). Host-plant specialization in pheromone strains of the European corn borer Ostrinia nubilalis in France. J Chem Ecol 30: 335-352.

Ponsard S, Bethenod M-T, Bontemps A, Pélozuelo L, Souqual M-C, Bourguet D (2004). Carbon stable isotopes: a tool for studying the mating, oviposition, and spatial distribution of races of European corn borer, Ostrinia nubilalis, among host plants in the field. Can J Zool 82: 1177-1185. 
Prokopy RJ, Bennet EW, Bush GL (1971). Mating behavior in Rhagoletis pomonella (Diptera: Tephritidiae): I. Site of assembly. Can Entomol 104: 97-104.

Prokopy RJ, Bennet EW, Bush GL (1972). Mating behavior in Rhagoletis pomonella (Diptera: Tephritidiae): II. Temporal organization. Can Entomol 104: 97-104.

Prokopy RJ, Roitberg BD (1984). Fruit fly - reply. Am Sci 72: 41-49.

Raymond M, Rousset F (1995). GENEPOP Version 1.2: population genetic software for exact tests and ecumenicism. J Hered 86: 248-249.

Rice WR (1984). Disruptive selection on habitat preference and the evolution of reproductive isolation: a simulation study. Evolution 38: 1251-1260.

Rice WR (1987). Speciation via habitat specialization: the evolution of reproductive isolation as a correlated character. Evol Ecol 1: 301-314.
Showers WB, Reed GL, Robinson JF, Derozari MB (1976). Flight and sexual activity of the European corn borer. Env Entomol 5: 1099-1104.

Thomas Y, Bethenod M-T, Pélozuelo L, Frérot B, Bourguet D (2003). Genetic isolation between two sympatric host-plant races of the European corn borer, Ostrinia nubilalis Hübner. I. Sex pheromone, moth emergence timing, and parasitism. Evolution 57: 261-273.

Turelli M, Barton NH, Coyne JA (2001). Theory and speciation. Trends Ecol Evol 16: 330-343.

Via S (1999). Reproductive isolation between sympatric races of pea aphids. I. Gene flow restriction and habitat choice. Evolution 53: 1446-1457.

Via S (2001). Sympatric speciation in animals: the ugly duckling grows up. Trends Ecol Evol 16: 381-390.

Weir BS, Cockerham CC (1984). Estimating F-statistics for the analysis of population structure. Evolution 38: 1358-1370. 